\title{
Teaching With Ignorance: Questions of Social Justice, Empathy, and Responsible Community
}

\author{
SHARON TODD \\ Stockholm Institute of Education
}

\begin{abstract}
This paper explores the limitations of empathy for the formation of community, particularly within social justice education. I begin with a discussion of the major tension within the idea of community - that it is founded at once on commonality and difference. Building in particular upon the work of Emmanuel Levinas, the paper articulates an understanding of community as a signifying encounter with difference that is not founded upon knowledge about the other, but upon a being-for and feeling-for the other. Focusing upon the explicitly educational commitment to working out forms of relationality conducive to establishing community and social justice across social differences, I ask how might teaching with ignorance, as opposed to teaching for empathy, bring us closer to the being-for others that marks our ethical engagement with other people and engenders our responsibility to the collective?
\end{abstract}

KEYWORDS: Empathy, social justice, community, responsibility, Levinas, being-for, feeling-for, tcaching, Derrida, Bauman.

Both within educational theory and political philosophy, calls for a conception of justice that lie beyond a liberal distributive paradigm are deeply embedded in appeals to community. ${ }^{1}$ Community, as a responsible mode of social togetherness, is seen to be in the service of redressing social oppression and civil breakdown between (and amongst) members of social groups, be these defined ethnically, racially, scxually, or economically. Despite a postmodern understanding within social justice education that differences, like identities, are shifting and mutable, community nonetheless is located in those moments where a coming together across differences is made possible. What it means to come together as a time of connectedness and sharing suggests that there is some common understanding that supersedes our specific social 
locations. It is invested with the moral and political possibility that gaining common ground is a forerunner to assuming responsibility. Community and responsibility would then seem to arise at the moment difference ceases to be an impediment to mutual understanding. On this view, community brings and unites us together in spite of the radical difference between our experiences, and thus bridging the gulf that separates each of one us holds promise for treating each other with the respect each of us deserve. One of the ways in which social justice education has sought to promote such an idea of responsible community is through calls for empathy, that is, through feeling with another's experience in order to promote a shared understanding that has moral and political implications.

On the surface, empathy as an act of fellow-feeling would appear to be constructive toward building unity out of diversity and commonality out of difference. ${ }^{2}$ It would seem to provide the idea of community with the affective glue that binds individuals into a socially cohesive group. However, implicit in this idea of community is an illusion of "social wholeness" (Young, 1990, p. 232) which risks submerging the very differences that social justice education seems so adamant to respect into a collective totality where singularity no longer holds any moral or political meaning. The idea, then, that singularity might be sacrificed at the altar of community seems to miss the point of ensuring that all differences, irrespective of understanding, can be responsibly attended to. After all, does not each of us have a responsibility to others even when understanding their experience is not possible? Responsibility conceived as a relation that respects the unique and unknowable distinctness of another person (Levinas, 1969, 1998a, 1998b) would appear, on the one hand, to reside within the purview of the aims of social justice education in respecting experiences that fall outside the terms of dominant discourses and social relations, and, on the other hand, to exist in direct opposition to the formation of community and the commonality it seeks to establish. So the difficulty of thinking about community and responsibility together lies in the tension between the commonality that is assumed by community, and the attention to singularity that responsibility commands.

One of the urgent demands in seeking social justice is to figure out how community may be created and sustained in the face of what, at times, appear to be overwhelming odds at getting people to interact and communicate across their differences. Part of the task of creating just possibilities for living well together is to form alliances to others that bridge the gulf between our disparate experiences in ways that 
recognize that we cannot have firsthand knowledge of another's life. How can people interact with one another across their myriad differences to form a common ground and at the same time have those differences respected? Is empathy the answer?

Such questions, I argue, become particularly acute within social justice education, given that empathy is thought to embody both moral force and political possibility (cf. Boler, 1999). Unlike other emotions, empathy is not simply considered to be one affective response among many, but it is seen to have ethical legitimation in a way that other emotions, such as pity and guilt, do not usually enjoy. In fact, viewed as an explicitly moral emotion, empathy is the very form of attachment seen to be necessary for living responsibly together. It is this emphasis on what empathy appears to offer to our sense of togetherness that has made it so prevalent, in my view, within social justice education. The idea is that the more we feel with an other, the better we are able to have a sense of what matters to her or him and, consequently, come to be with the person better. The ultimate hope is that our capacity for empathy may contribute to a mode of being with others that furthers the moral and political project of justice.

However, what I pursue in the present paper are three points that disrupt the privileging of empathy as an answer to establishing a responsible mode of social togetherness. First, I explore how moments of social togetherness also might signify something other than commonality and conventional notions of community. Following Levinas, I expose the tensions between the common and the unique that such moments invoke and what those tensions have to offer our understanding of teaching for social justice. Thus, one of the guiding questions of this paper is to what degree can community function as a signifying relation with difference that takes into account the very difference that gives rise to the promise of community in the first place? Second, Zygmunt Bauman's (1995) understanding of different modalities of togetherness, particularly the distinctions he makes between being-with and being-for others, offers us a point of departure for considering the limits of empathy as an answer to the ethical problem of social togetherness. That is, coupled with Levinas' understanding of responsibility as a being-for the unique other, I emphasize here that it is not knowledge about the other through empathy that is important for community, and for social justice education more specifically, but the orientation to the other's unknowability as a learning from the other. A second question, then, is how might we conceive of social togetherness so that responsibility for 
the other's singularity is not collapsed into a uniform notion of community? Third, in focussing upon the explicitly educational commitment to working out forms of relationality conducive to establishing community and social justice across social differences, I ask how might teaching with ignorance, as opposed to teaching for empathy, bring us closer to the being-for others that marks our ethical engagement with other people and engenders our responsibility to the collective?

\section{Community and the Pedagogical Question}

I have posed above a central tension in promoting an idea of community: it wishes to respect difference - ethically and responsibly - and yet risks subsuming difference under the sign of commonality. Critchley (1999) notes in his commentary on Levinas that "community has a double structure" (p. 227); it both relies upon the radical distinction between self and other that makes an ethical relationship possible and upon an obliteration of that distinction in creating a unity between subjects. But how does this come about? Is it possible to simply rethink the terms of community differently, so that it no longer comes to mean commonality at all? If we turn to Levinas, we see that the political structure of community inherently rests upon the ethical structure of the self-other relation. What both Levinas (1969), and to a certain degree Derrida (1997), suggest, as we will see below, is that the project of justice must not lie in a new definition of community, but in a radical appreciation of how community emerges - and what is lost and gained in the process. Thus, community here is cast not so much as a political or social entity having fixed properties, but as a moment of signification through which subjects enact a form of social togetherness.

Central to community, and the equality and commonality it implies, is an understanding that our relations do not exist as though divorced from social context. Indeed, Levinas conceives of the ethical relation between self and other as already situated within community, signalled by what he refers to as the "third party:"

The third party looks at me in the eyes of the Other - language is justice. It is not that there first would be the face, and then the being it manifests or expresses would concern himself with justice; the epiphany of the face qua face opens humanity. The face in its nakedness as a face presents to me the destitution of the poor one and the stranger; but this poverty and exile which appeal to my powers, address me, do not deliver themselves over these powers as givens, remain the expression of the face. The poor one, the 
stranger, presents himself as an equal. His equality within this essential poverty consists in referring to the third party, thus present at the encounter, whom in the midst of his destitution the Other already serves. He comes to join me. $(1969$, p. 213)

What Levinas proposes here is that two simultaneous relationships are made possible in an encounter with the other. The dyadic ethical relation between self and other, or I and stranger, constitutes the basis for what Levinas will later refer to as responsibility at the same time that the face of the other signifies to the I "the whole of humanity" (1969, p. 213). Levinas does not see these relations as lying in sequence; rather they present the double consequence of signification: that is, the face signifies destituteness and therefore commands from the self a response that is truly ethical while also signifying, through the third party, all others within humanity. When the other joins me, she joins me in community and is with me in serving the third party. Together, in community, justice is made possible.

Both the ethical relation and the political relation, then, appear as processes of signification. What is highlighted here is that the copresence of subjects, the co-incidence of self and other (and the third), can only emerge from a signifying encounter with difference. There is no co-existence in togetherness possible without the disparity of difference, without there being a recognition that the other is not-me. For Levinas, "human community [is] instituted by language, where the interlocutors remain absolutely separated" (1969, pp. 213-214). Thus, what Levinas insists on is an understanding of community that is both coincident and non-coincident, or as Critchley (1999) puts it, "community is the coincidence of coincidence and non-coincidence, what Levinas calls, in a rather uncomplicated manner, 'human fraternity" (p. 227). The signification necessary for establishing this community with a double structure (i.e., the other's face signifying its own separateness, alterity, and destituteness as well as the third and the whole of humanity) also accomplishes the possibility for justice and ethics by putting the self into question (Levinas, 1969 , p. 213). ${ }^{3}$ This questioning does not arise out of what others have to say (e.g., they do not necessarily literally question me), but in the fact that they are others, absolutely different from myself. My encountering others challenges me and compels me to ask, "who am I?" in relation to them. Thus who "I" am must continually be (re)defined against this radical alterity through my response. And such a response, for Levinas, is nothing short of welcoming the other in this moment of encounter: 
Equality is founded in this welcoming of the face, which is already my responsibility in his regard, and where accordingly he approaches me from a dimension of height and dominates me. Equality is produced where the other commands the same and reveals himself to the same in responsibility; otherwise it is but an abstract idea and a word. It cannot be detached from the welcoming of the face, of which it is a moment. (1969, p. 214)

Equality, then, is only possible because the other's alterity demands a response from me. Meeting the other as equal is an unsettling and provocative experience where the "I" cannot remain aloof from the community in which the person finds oneself. That is, the self is caught in an unavoidable response to the other (and to all the other signifies) in a way that implicates the person in the co-existence she or he shares with others and to the possibilities it opens up for the future - to the limitless possibilities of justice. In his commentary on Nietzsche's call for a community with future philosophers, Derrida writes of the extraordinary demand that community makes on us:

A double responsibility which doubles up again endlessly: I must answer for myself or before myself by answering for us and before us. I/we must answer for the present we for and before the we of the future, while presently addressing myself to you and inviting you to join up with this 'us' of which you are already but not yet a member. (1997, p. 37)

With such demands structuring the advent of community - the responsibility to invite and welcome others as members into the fold of fraternity or human collectivity, where everyone is equal and shares a common pursuit of justice - is coterminous with the virtual disappearance of disparity and separateness in laying claim to community. How do we answer the other(s) in order to promote conditions for future coexistence in ways that address the particularity of the you? The emphases, both for Levinas $(1969,1998 \mathrm{a})$ and Derrida (1997), on the importance of welcoming and address, suggest that community is a continuously on-going practice that negotiates a difficult ethical path. In these views, community is not a consequence of an encounter with others, but a practice of encountering others. Commonality, equality, and shared responsibility can only ever be derived from the presence of difference within community, a difference that constantly threatens to break in upon and dissolve the communal bond. Yet, equally paradoxically, it is precisely in attending to this difference, to others as others, that enables formations of community, formations that take seriously the burden of justice, that is, the burden of making decisions, evaluations, comparisons, and judgements. This 
view of community is hence incomplete, dependent as it is on the changing quality of relationality and interaction that shapes social togetherness and stands in contrast to conventional notions of community. Conventionally speaking, requiring that some commonality be established with those who are different from me or us means that the goal of our interactions operates within a logic that cannot fully recognize difference as necessary to the formation of a responsible community. That is, even when difference is a point of departure for communicating with someone, difference itself is not a defining feature of either community or responsibility. Community on this account is understood as an object or entity that one negotiates one's attachment to - as though it pre-exists the very subjects that participate in it. But, by virtue of its signifying function, I want to suggest that community as a communicative process has an eminently pedagogical nature that perhaps goes a long way to explain why empathy appears so appealing to its formation.

There is an implicit teaching and learning that must transpire in the communicative encounter for there to be community at all. Without this pedagogical force, community would be reduced to a contrivance rather than effectuating the alteration of self and society that it in fact demands. What I mean by this is that unity cannot be established by fiat, and as soon as any alteration is established, a new unity must be forged. Such alteration, if we are to follow Derrida and Levinas on this point, comes about because the self is called into question through an encounter with the other and must assume responsibility for that other. The particular obstacles that face people in coming together to speak and listen to each other lie precisely in our difficulties to be questioned, in our resistances to change, and in our uncertainties about how to respond. It is what makes forming communities out of infinite differences so difficult in the first place. As Lingis puts it:

To question someone is not simply to make oneself a receptor for information that one will soon reissue; it is to appeal to another for what is not available to oneself .... To address someone is not simply to address a source of information; it is to address one who will answer and answer for his or her answer. (1994, p. 87)

Community is so difficult to create and sustain precisely because the self is at stake in communicating with others. The very point of community for projects of social justice is that it presents us with the hope of transformation at both the level of the self and the society, and through this transformation we edge ourselves closer to peace and justice. It assumes, therefore, that the ways we communicate and 
establish forms of social togetherness involve learning from others and attending to our implications in that learning. But if community is an arduous process of being with others that depends equally on our capacity to learn from others and on our capacity to welcome and respond to others, then how might we think about the role of empathy? For if empathy is a feeling with others that bridges differences, to what degree does empathy embody a signifying relation to difference that evokes learning, welcoming, and responding?

\section{Responsible Togetherness: \\ From Being Aside to Being With to Being-for}

We exist together in many different ways according to social contexts. For instance, we are together differently in a classroom than we are at a political protest, or when we rally around signifiers of race and gender, or are simply walking on a crowded street in our neighbourhood. Each of these forms of togetherness involves certain patterns of interaction that shape what it is we expect from them. Bauman (1995) claims that while the interaction is different, forms of togetherness are enacted through three modalities of being, what he refers to as being-aside, being-with, and being-for. Each of these reveals what is at stake for the self in encountering the other. His understanding of how we are together, then, offers a way of thinking about what modes of togetherness are worthy of pursuit in promoting social justice in education. It also allows us to consider what degree empathy plays a role in establishing responsible community.

First, forms of togetherness are the settings in which people are initially "cast aside each other" (Bauman, 1995, p. 50). That is, people inhabit a shared space, yet are not at the centre of it; they have the modality of being-aside. ${ }^{4}$ Being together in this sense means that we exist tangentially, each one of us occupies space, but we do not interact in any significant way.

However, there is also possibility for interaction while we are together. As soon as one enters an encounter with another, one "moves into the modality of being-with," the second modality identified by Bauman (1995, p. 50). Being-with signals that one has relevance for another, but this, Bauman claims, is topical and transient. Being-with is a mode of communication that is constrained by the parameters of time and place whereby people may have interesting interactions, but are not transformed in any way by them. As a consequence, aspects of the self are engaged in ways that are normative and safe. As Bauman 
states, such encounters are conventional: "Conventions substitute concern with the rule for the concern for the partner of encounter .... The rule-governed togetherness, the being-with exhausted in the observance of rules, is a colony of hermits, an archipelago of oneresident islands" (p. 56). As such, being-with depicts a mode of interaction that is rooted in knowledge, understanding, and communicative transparency. Community, insofar as it holds potential for transformation, does not obviously rest here.

For Bauman, there are moments, however, when people actually break through convention and transcend the limitations of time and place. He writes of the third modality of togetherness:

Such another way of relating is being-for .... Being-for is a leap from isolation to unity; yet not towards a fusion, that mystics' dream of shedding the burden of identity, but to an alloy whose precious qualities depend fully on the preservation of its ingredients' alterity and identity. Being-for is entered for the sake of safeguarding and defending the uniqueness of the Other; and that guardianship undertaken by the self as its task and responsibility makes the self truly unique, in the sense of being irreplaceable; no matter how numerous the defenders of the Other's unique otherness may be, the solf is not absolved of responsibility. Bearing such a task without relief is what makes a unique self out of a cipher. Being-for is the act of transcendence of being-with. (1995, pp. 51-52)

In other words, an encounter with the Other crupts through the space of convention without intent or telos. The being-for the Other is a togetherness born out of the immediacy of interaction, a communicative gesture that does not have as its end anything except its own communicativeness, its own response. And it is in this moment of transcendence that convention has no meaning, has no currency within the bounds of the relationship. Moreover, for Bauman, the being-for invokes commitment:

Eyes stop wandering around and glossing over moving shapes, eyes meet other eyes and stay fixed - and a commitment shoots up, apparently from nowhere, certainly not from previous intention, instruction, norm; the emergence of commitment is as much surprising as its presence is commanding. (1995, p. 53)

The commitment Bauman writes of here is one born out of the exigency of the face-to-face encounter with the Other. It is a commitment that inevitably arises in an open and direct communication; and it is a commitment one avoids, for instance, when one averts one's eyes away from someone, like when a teacher asks a question to the class only to 
find all students' eyes darting to the floor. But what is most remarkable is how being-for ushers in a responsible subjectivity that is not located in what one knows about someone, but in a communicative approach to someone rooted in one's capacity to feel.

Levinas (1998a) understands an encounter with the Other as constituting a modality not simply of being-for, but of being responsible for the other. This "for" is, as John Llewelyn (1995, p. 145) notes, always rooted in sensibility, in the quality of relationality that lies outside language, outside knowledge. "Knowing, identification which understands or claims this as that, understanding, then does not remain the pure passivity of the sensible" (Levinas, 1998a, p. 16). Thus, the ethical encounter is that which transcends being-with while remaining firmly grounded in feeling and sensation.

There are two distinguishable characteristics of the being-for that are helpful to this discussion. First is that the encounter with the Other is a relation with the unknowable mystery of the other person.

If the relationship with the other involves more than relationships with mystery, it is because one has accosted the other in everyday life where the solitude and fundamental alterity of the other are already veiled by decency. One is for the other what the other is for oneself; there is no exceptional place for the subject. The other is known through sympathy, as another (my)self, as the alter ego. (Levinas, 1998a, p. 83)

What Levinas articulates here is that while we can have a shared reality with the Other, feelings such as sympathy (and, I suggest, empathy) require renouncing the irreducibility of self and other through their seeking out knowledge about the other. This means, then, that in everyday communication within social situations such as teaching and learning we of course do empathize, commiserate, sympathize, and pity, and these emotional events can connect us in profound ways. For Levinas (1969), it is not that these everyday feelings are unimportant, it is just that they have little to do with the necessary maintenance of alterity, an alterity that is revealed in the "straightforward" encounter with the face (p. 203). ${ }^{5}$ Thus, feeling with others cannot lead to transcendence, for it blurs the distinction between self and other. As any feeling-with does, empathy might bridge the divide of difference through understanding and knowledge, but it does so at the cost of respecting the Other's fundamental difference. In this way, empathy forecloses the double structure of community, for it lands squarely on the side of commonality (i.e., through shared understanding) and makes impossible the survival of singularity that difference signifies. 
Second, the encounter with the Other requires the self to depose its ego, its intentionality and consciousness, in the service of the Other, as it feels and senses its way to a response to the other. Responsibility for the Other, being-for the other, means that the self is no longer a selfregulating agent, but is passively open and exposed. Although we may respond to what someone is saying, although we may feel with the Other in her or his articulated pain or pleasure, the ethical relation lies in attending to the approach of the Other in such a way as to limit one's own self concern. The self feels for the Other in such a way as to disrupt its own pleasures, its own ego enjoyments. "It is the passivity of beingfor-another, which is possible only in the form of giving the very bread I eat. But for this one has to first enjoy one's bread" (Levinas, 1998a, p. 72). Counter to our more commonplace understandings, responsibility is neither ego-directed nor consciously chosen. ${ }^{6}$ When I feel-for the Other, I am in a state of exposure, a nakedness Levinas would say, that makes me susceptible to the Other's needs. Thus, my feeling-for is a disinterested, non-ego-invested feeling that emanates only through the encounter with the Other, as opposed to being generated from within the subject. It is the supreme example of "being moved," "being touched," and "being affected." That is, being becomes inextricably bound to feeling through a passive encounter with difference. In this sense, a responsible community would entail a mode of feeling that does not seek to end our differences, but one that has generative potential to sustain open modes of relationality across differences. Understanding and knowledge, while essential for making judgements, comparisons, and priorities can only emerge, for Levinas, out of an openness through which the self is capable of transformation.

It is precisely because it is assumed that empathy has the power to disrupt conventional ways of being together and transform our understandings of self and other that it is seen to be such an important focus for social justice education. Yet, commitment and responsibility, as Levinas (1998) and Bauman (1995) suggest, erupt through forms of communication that are not pre-designed. Our very encounter with difference poses as a surprise that cannot be known beforehand. Likewise our responses to others cannot be made from easy recipes, as if those responses could be delineated prior to our meeting other persons. Thus, it is non-knowledge and our orientation to learn from others in the moment of encounter that characterize the double structure of community. The non-intentional quality of feeling that nourishes the possibility of community turns any demand for empathy into an impossibility. That is, how can teaching for social justice ask 
students to empathize as a condition of creating deep communal bonds, when not only is no feeling within anyone's sphere of control, but when the very conditions of community and responsibility both imply that feelings cannot be demanded, but must be given.

In terms of the actual feelings of empathy (and not just the pedagogical demand for them), what remains important to consider is how empathy, through its impulse to overcome difference and partake in a shared reality, focuses upon what we can know of the other's experience. To suggest that students or teachers ought to "put themselves in the other's shoes" seems to be encouraging a shutting down of the very opportunities for communicative openness and learning from the other that social justice education works so hard to achieve, and that responsibility community would appear to require. It is not that we should not empathize. This seems to me as equally an impossible request as is the demand for empathy. The fact is, we do empathize regularly with others' suffering, enjoyment, and perspectives. My point is that empathy cannot but mask, despite our best intentions, the other's radically different feelings, experiences, and needs. Empathy necessarily leads to questionable assumptions about how the other is ultimately somewhat like you, and that what you feel is the same as the other's feelings.

But if teaching empathy is not the answer to encouraging forms of responsible community that can respect difference, then what can be the alternative? How might we rethink teaching itself as a being-for; that is, as a practice that does not merely demand students to be for others, but that sees itself as a mode of togetherness that displays the openness requisite to living responsibly across difference?

\section{Teaching with Ignorance, or Teaching as a Response to a Question}

Proposing that ignorance can occupy a necessary place in teaching, and a necessary place in the modality of being-for that characterizes responsible togetherness, verges on the absurd. Is not the problem for building community about not having enough knowledge about social, cultural, ethnic, racial, sexual, and religious differences? Does not empathy, insofar as it is a feeling through which the self comes to share in the experience with another, precisely offer this knowledge? Becoming teachers frequently say to me that empathy is what gives them the understanding of diverse communities that are represented in their classes. It gives them access to others' lives in ways that make 
them feel connected to their students. It allows them to get to know their students better. However, I suggest to them that knowledge alone cannot solve the issue of living well and responsibly together. Not only is it for the other to say whether or not he or she has felt understood, but even more importantly, our knowledge at best cannot capture the full range and complexity of another's life. Nor can the multiple layers of what it means for students to belong to communities be contained within a teacher's understanding. The sheer plurality of communities, and the shifting nature of their formation make any appeals to knowledge equally absurd. The impossibility of knowledge and the certainty that it ostensibly brings does not relieve us, however, of our responsibility to our students and for creating communities across difference. On the contrary, the whole possibility of responsibility is put into sharp relief against of this very impossibility. Following through on the idea of that being-for the other entails feelings that contribute to the formation of both responsibility and community, the point becomes to consider teaching as an approach that cannot know beforehand what it is seeking.

As we have seen, the encounter with difference that produces community is an eminently pedagogical one. Similarly, the community that social justice education aims to forge is also pedagogical, though not in the sense that teachers have to encourage students to feel empathy or have to themselves empathize with their students. Rather, where the pedagogical insistence lies is in terms of how the other calls me into question, requiring me to listen and learn from her in order to respond responsibly. Teaching with ignorance requires a suspension of presuming to know. It means that community lies not in some predefined feeling, but in our responses to students that are conditioned upon our capacity to be moved by the singularity of the other's experience. It is from a place of non-knowledge, then, where my responsibility becomes heightened. If I am exposed in a gesture of communicative openness to the Other, where I can feel-for the other, I can listen, attend, and be surprised. It is only in this way that the Other can affect me, move me, touch me. Out of this state of ignorance, where I am not laying claim to another's experience, the being-for initiates a togetherness that disrupts the very transparency of communication and the conventional modes of togetherness we find ourselves in, and in this it becomes truly radical.

Classrooms are sites of signification where the ongoing formation of community is continually at work. The double-bind of community combined with the ethical imperative to be-for the other means that 
education lives through these tensions, moving between and through forms of social togetherness that cannot be fixed with appeals to empathy. I have proposed here that teaching as a response to a question, a response that can only be rooted in a moment of unknowability, contributes to understanding teaching as itself a moral and political practice. Highlighting community as a signifying practice which, on the one hand, allows for the dissolution of convention and accepted communal bonds (when, for instance, the being-for interrupts commonplace forms of togetherness) and, on the other hand, establishes commonality and shared understandings in community (when, for instance, the singularity of the face signifies that the self is responsible for many others and not just a singular Other), means coming to grips with our own implications in those relationships. Teaching for empathy, as it can only ever seek to suture over differences, fails to engage with the problem - and the urgency - of how responsibility is not just a matter of establishing commonality, but about a pursuit of justice that requires working through the aporia posed by community and the difference which both makes it possible and impossible simultaneously.

Thus teaching with ignorance is not the answer, as if we can teach this way all of the time. Instead, I see it as a way of thinking through some tensions for creating and sustaining forms of social togetherness that respect difference. Teaching with ignorance means responding to the commitment I have for the other, a commitment that makes possible forms of community that are not rooted in the content of what is said, but in the approach to the mystery of the other. It allows for attentiveness to singularity and specificity within the plurality that is our social life. It is only when we recognize and embrace our ignorance that we can truly begin to learn from the stories that others have to tell. The question of what attaches us and holds us together, and what this means for more just relations in the present and future, cannot therefore be answered with an appeal to empathize with others better. Rather, what I am suggesting is that just forms of togetherness lie in the eminently disruptive time of the communicative approach itself and the feeling-for that this demands.

\section{NOTES}

1. Community can, of course, be defined in many different ways, and some authors eschew its value altogether. Iris Marion Young (1990), for instance, in putting forth a notion of social justice that puts domination and oppression ... develops a notion of "city life" as a model for social togetherness that moves explicitly away from the emphasis on community 
(pp. 226-256), which she sees as having an illusory desire for social wholeness. Yet, its rather ubiquitous presence in social justice education suggests to me that it needs serious unpacking precisely with respect to its dream of commonality. Thus, rather than mobilize new metaphors, I investigate here the possibility and limitations of community as an expression of.

2. See my discussion of the different ways empathy has been defined and its relation to ethical possibility in Todd (2003).

3. As Robert Gibbs (2000) puts it, "We begin with questions. Not the questions I ask, but the question I am asked. When we listen, we hear the questioning that comes from the other person. I need to listen to be questioned in a way I cannot question myself - and in listening to the question I am shown the questioner. In the question the other appears as a teacher who questions me in ways I cannot anticipate" (p. 32).

4. This is how Levinas characterizes Heidegger's being-with. Viewing it as a kind of being-aside, Levinas sees that this form of togetherness cannot lead to the emergence of responsibility and remains caught up in an individual's solitude.

5. The full quote reads: "No fear, no trembling could alter the straightforwardness of this relationship, which preserves the discontinuity of relationship, resists fusion, and where the response does not evade the question" (Levinas, 1969, p. 203).

6. This is not, of course, to say that the decisions we make regarding our treatment of others is without any significance. It is merely to say that the (metaphysical) preconditions for such decisions to be made lie in the sentient, not conscious, subject.

Author's Address:

Stockholm Institute of Education

Department of Social and Cultural Studies

Konradsbergsgatan $5 \mathrm{~A}$

Box 34103

10026 Stockholm

SWEDEN

EMAIL: sharon.todd@ibs.se

\section{REFERENCES}

Bauman, Z. (1995). Life in fragments: Essays in postmodern morality. Oxford: Basil Blackwell.

Boler, M. (1999). Feeling power: Emotions and education. New York: Routledge. 
Critchley, S. (1999). The ethics of deconstruction: Derrida \& Levinas. Edinburgh, Scotland: University of Edinburgh Press.

Derrida, J. (1997). Politics of friendship (G. Collins, Trans.). London: Verso. Gibbs, R. (2000). Why ethics? Signs of responsibility. Princeton, NJ: Princeton University Press.

Levinas, E. (1969). Totality and infinity: An essay on exteriority (A. Lingis, Trans.). Pittsburgh, PA: Duquesne University Press.

Levinas, E. (1998a). Otherwise than being or beyond essence (A. Lingis, Trans.). Pittsburgh. PA: Duquesne University Press.

Levinas, E. (1998b). Uniqueness. In E. Levinas (Ed.; M.B. Smith \& B. Harshav, Trans.), Entre nous: On thinking-of-the-other (pp. 189-196). New York: Columbia University Press.

Lingis, A. (1994). The community of those who have nothing in common. Bloomington, IN: Indiana University Press.

Llewelyn, J. (1995). Emmanuel Levinas: The genealogy of ethics. London: Routledge.

Todd, S. (2003). Learning from the other: Levinas, psychoanalysis and ethical possibilities in education. Albany, NY: State University of New York Press.

Young, I.M. (1990). Justice and the politics of difference. Princeton, NJ: Princeton University Press. 